\title{
ESCAYOLA ALIGERADA CON SÓLIDOS CELULARES
}

\author{
(LIGHTWEIGHT PLASTERBOARD WITH SOLID CELLULAR)
}

Mercedes del Río Merino y José D. Domínguez, Arquitectos

Dpto. de Construcciones Arquitectónicas y su Control. E. U. de Arquitectura Técnica. Univ. Politécnica de Madrid

Francisco Hernández Olivares, Arquitecto

Dpto. de Construcción y Tecnología Arquitectónica. E. T. S. Arquitectura. Univ. Politécnica de Madrid

ESPAÑA

Fecha de recepción: $26-\mathrm{X}-98$

\begin{abstract}
RESUMEN
El presente trabajo pretende estudiar cuáles de las diversas cargas celulares que se utilizan en el mercado de la construcción de edificios como aligerantes, son las más adecuadas para la prefabricación de elementos de escayola.

Se propone, por tanto, un modelo de material compuesto, escayola + carga, con el que se conseguiría reducir el peso de los prefabricados de escayola en beneficio de un mayor rendimiento en la puesta en obra, con un menor número de roturas y desconchones en el transporte hasta la misma.
\end{abstract}

\section{SUMMARY}

The following paper pretends to analyze the different cellular fillers, that are mainly used in building construction as lightweighters, in order to stablish the most suitable ones for the manufacture of plasterboard.

A model of compound of gypsum +filler is proposed here which would greatly reduce the weight of the plasterboard panels to improve the construction efficiency on the building site and to reduce the fracture risks in the transportation to the building site.

\section{INTRODUCCIÓN}

Se realiza un estudio comparativo de aquellos materiales compuestos constituidos por una matriz de escayola a la que se le añaden distintas cargas, en forma de gránulos, para lograr una disminución de la densidad de dicha matriz.

El objetivo perseguido es determinar cuál de estas cargas, todas de frecuente uso en la construcción de edificios, es la más adecuada para utilizarla en la elaboración de productos prefabricados más ligeros, en forma de placas o paneles que sustituyan los similares ya existentes de escayola sin aditivar.

Distinguimos, entre las cargas de relleno utilizadas, dos grupos bien diferenciados:
a) Áridos ligeros.
b) Granulados ligeros.

Se realizan probetas de cada uno de los distintos materiales compuestos, escayola+carga, así como ensayos de resistencia mecánica (flexotracción, compresión, dureza Shore C) sobre las mismas, a efectos de determinar cuál aporta una mejor relación densidad/resistencia mecánica.

\section{MATERIALESUTILIZADOS}

\section{Matriz}

\section{Escayola}

Se realiza un estudio previo sobre la escayola, como matriz principal, para que nos sirva de referencia en el análisis de los distintos materiales compuestos que se estudian.

La escayola que se utiliza a lo largo de todo el trabajo es E-35. Escayola especial, constituida, fundamentalmente, 
por sulfato de calcio semihidrato, con la posible incorporación de aditivos reguladores del fraguado, con mayor pureza que la escayola E-30 y con una resistencia mínima a flexotracción de $35 \mathrm{kp} / \mathrm{cm}^{2}$. Se utiliza en trabajos de decoración, en la ejecución de elementos prefabricados para techos y en su puesta (1).

\section{Cargas}

\section{Áridos ligeros}

Se propone la realización de probetas prismáticas de escayola aligeradas mediante áridos ligeros.

Dentro de los áridos ligeros, los más frecuentes de encontrar en el mercado de la construcción española son:

\section{- Arcilla expandida \\ - Perlita \\ - Vermiculita exfoliada}

\section{Granulados ligeros}

Se propone la realización de probetas prismáticas de escayola aligeradas mediante granulados ligeros, los más frecuentes de encontrar en el mercado de la construcción en España son:

\section{. Poliestireno expandido.}

. Corcho natural.

Con todos ellos se procede de la siguiente forma:

. Búsqueda bibliográfica y documental.

. Memoria, donde se desarrollarán los siguientes puntos:

Descripción del producto. Características físicas y mecánicas. Aplicaciones en el campo de la construcción de edificios y, más concretamente, en productos prefabricados. Aplicaciones con yeso o escayola.
. Realización de probetas prismáticas de 4x4×16 cm. Una amasada por serie.

Estudio de la estabilidad del compuesto. Análisis del peso de las probetas, reducción del mismo, en comparación con probetas de escayola sin aditivar.

- Realización de ensayos de resistencia mecánica: flexotracción, compresión y dureza Shore C. Conclusiones de los ensayos, tomando como referencia probetas iguales de escayola sin aditivar.

. Por último y una vez analizados todos los compuestos de escayola+cargas ligeras, se hace una comparación conjunta, para concluir en la posible validez de estos materiales como aligerantes de paneles prefabricados de escayola.

\section{ADICIÓN ALAESCAYOLADE ÁRIDOSLIGEROS}

Ya en el siglo II a.C, los ingenieros romanos conocían las cualidades de los áridos ligeros, prueba de ello es la construcción de la bóveda del Panteón en Roma, realizada con una argamasa aligerada con piedra pómez.

Fue en 1917 cuando se generaliza su uso en construcción, debido a que es, en este momento, cuando se consiguen fabricar áridos ligeros industriales. S.J. Hayde desarrolló en los EEUU un proceso industrial de expansión de arcillas mediante un horno tubular giratorio. Los áridos conseguidos mediante este sistema se aplicaron en la construcción de edificios a través de la fabricación de hormigones ligeros (2).

\subsection{ARCILLAEXPANDIDA}

\subsubsection{Obtención}

Se obtiene sometiendo arcillas especiales a un proceso de cocción a temperaturas de $1.200^{\circ} \mathrm{C}$ en grandes hornos rotatorios. Mediante este tratamiento, la arcilla se

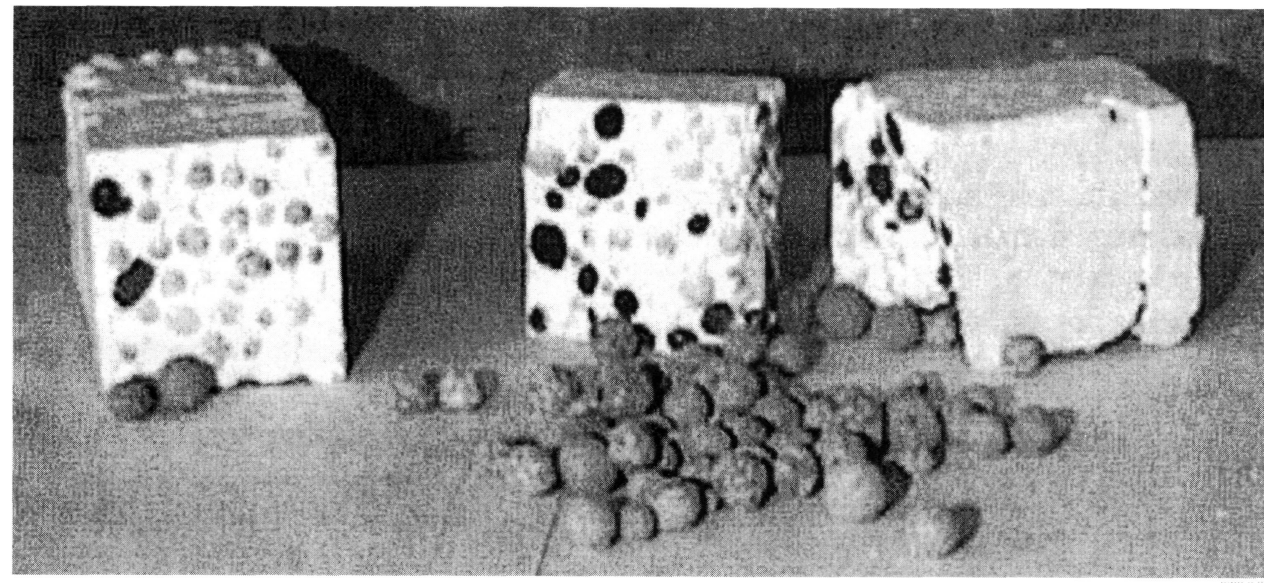

Arcilla expandida. 
transforma en gránulos esféricos porosos y ligeros, con una superficie resistente de color pardo y un interior grisáceo, formado por innumerables burbujas que contienen aire estancado, esta característica le otorga un poder altamente aislante y, a la vez, permite el libre paso del vapor de agua.

Es un producto químicamente neutro, que no desprende gases ni malos olores, es imputrescible y no atacable por parásitos, hongos o roedores. No le afectan las sustancias químicas y es altamente resistente a las heladas y a los cambios bruscos de temperatura (3).

Sus aplicaciones en el campo de la construcción son muy diversas, sobre todo como aligerante de hormigones.

No se han encontrado referencias bibliográficas ni documentales sobre la arcilla expandida como aditivo de la escayola.

\subsubsection{Plan de ensayos}

Se realizan varias series de probetas prismáticas de dimensiones $4 \times 4 \times 16 \mathrm{~cm}$, según norma.

Con las primeras series que se confeccionan se tantea el porcentaje máximo de arcilla, sobre peso de la escayola, que admite la mezcla, manteniendo la trabajabilidad de la misma.

Se trabaja con relación agua/escayola $(\mathrm{A} / \mathrm{E})$ de 0,8 y porcentajes del $20,40,50$ y $60 \%$. Concluyendo que es más favorable añadir el $60 \%$, como máximo.

La arcilla expandida con la que se realizan las probetas es la F-3, granos de diámetro comprendido entre $3-8 \mathrm{~mm}$ y densidad $\left(350 \pm 50 \mathrm{~kg} / \mathrm{m}^{3}\right)$.

Como en estas series de probetas se observa que la resistencia a flexión disminuye un $46,7 \%$ de media, con respecto a la escayola sin aditivar, se realiza una nueva serie en donde se añade un $1 \%$ de fibra de vidrio, sobre el peso de la escayola, para comprobar si esto es efectivo, con el fin de obtener valores mayores de resistencia mecánica. Se ensayan a flexotracción y compresión. La tabla 1 contiene los resultados de estos ensayos.

\subsubsection{Conclusiones}

La adherencia entre los granos de arcilla expandida y la escayola parece ser lo suficientemente importante sólo en granos de diámetros a partir de $5 \mathrm{~mm}$; esto se confirma al observar la superficie de fractura, donde los granos gruesos aparecen partidos, desprendiéndose los granos de menor diámetro.

La rotura es irregular, ya que se busca la rotura que suponga menor energía, formándose la superficie de fractura en zonas de la probeta con menos cantidad de granos de arcilla.

\section{Dureza}

Los valores de dureza Shore C, son similares a los de la escayola sin aditivar, realizada con la misma relación $\mathrm{A} / \mathrm{E}$.

\section{Peso}

El añadir a la escayola un $60 \%$ de arcilla expandida supone una reducción del peso frente a la escayola sin aditivar de un $21,13 \%$ de media.

\section{Resistencia a flexotracción}

La reducción de la densidad del material compuesto conduce, en general, a una disminución de los valores de resistencia a flexotracción, que, en este caso concreto, es

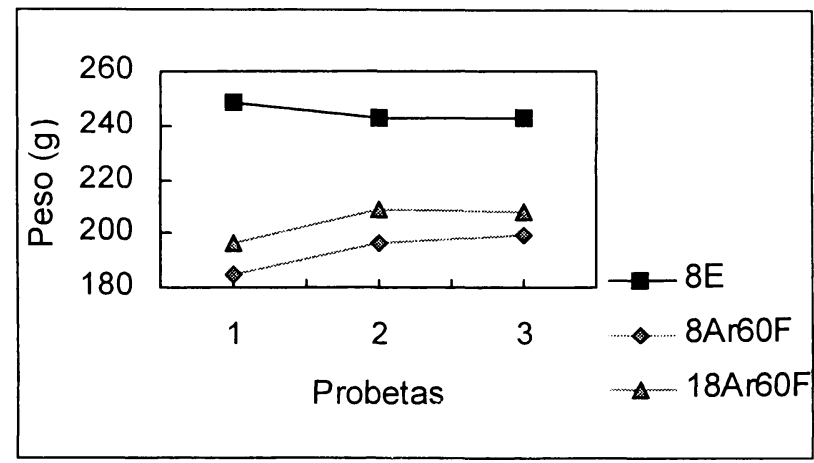

Figura 1.- Pesos de las dos series de probetas de escayola y arcilla expandida, sin fibra de vidrio y con fibra de vidrio (1\%) y de la escayola sin aditivar.

TABLA 1

\begin{tabular}{||l|l|l|l|l|l|l||}
\hline Serie & Tipo E & A/E & $\begin{array}{l}\text { Tipo } \\
\text { arcilla }\end{array}$ & $\begin{array}{l}\% \\
\text { arcilla }\end{array}$ & $\begin{array}{l}\% \\
\text { Fibra. }\end{array}$ & Denominación \\
\hline 8 & E-35 & 0.8 & F-3 & $60 \%$ & ------ & 8Ar60F \\
\hline 9 & E-35 & 0.8 & F-3 & $60 \%$ & $1 \%$ & 18Ar60F \\
\hline
\end{tabular}


del $46,7 \%$ de media y que al añadir un $1 \%$ de fibra de vidrio E, de $25 \mathrm{~mm}$ de longitud, mejora a un $23,88 \%$, también de media.

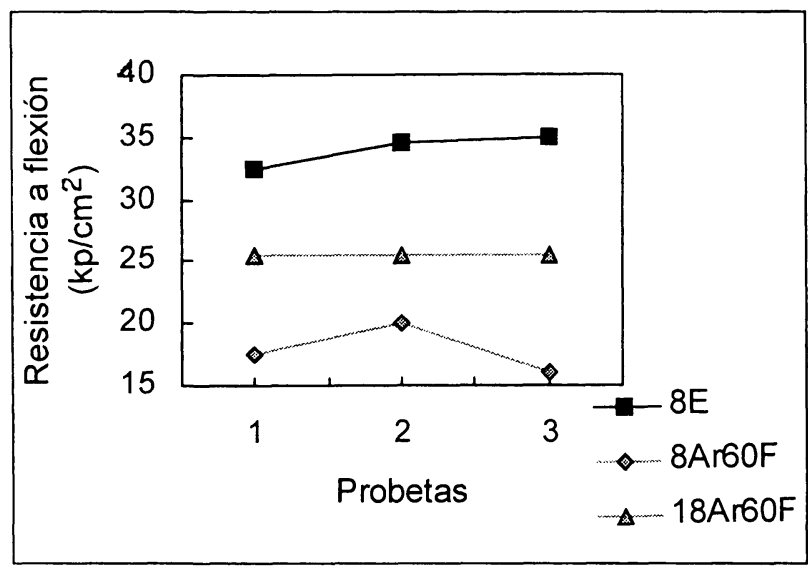

Figura 2.- Resistencia a flexión para las dos series de probetas de escayola y arcilla expandida, sin fibra de vidrio y con fibra de vidrio (1\%) $y$ de la escayola sin aditivar.

\section{Resistencia a compresión}

Los valores de resistencia a compresión mejoran frente a los de la escayola sin aditivar del orden medio de un $8,7 \%$.

Este aumento se incrementa con la incorporación de un $1 \%$ de fibras de vidrio $\mathrm{E}$, de $25 \mathrm{~mm}$ de longitud, en un $17 \%$.

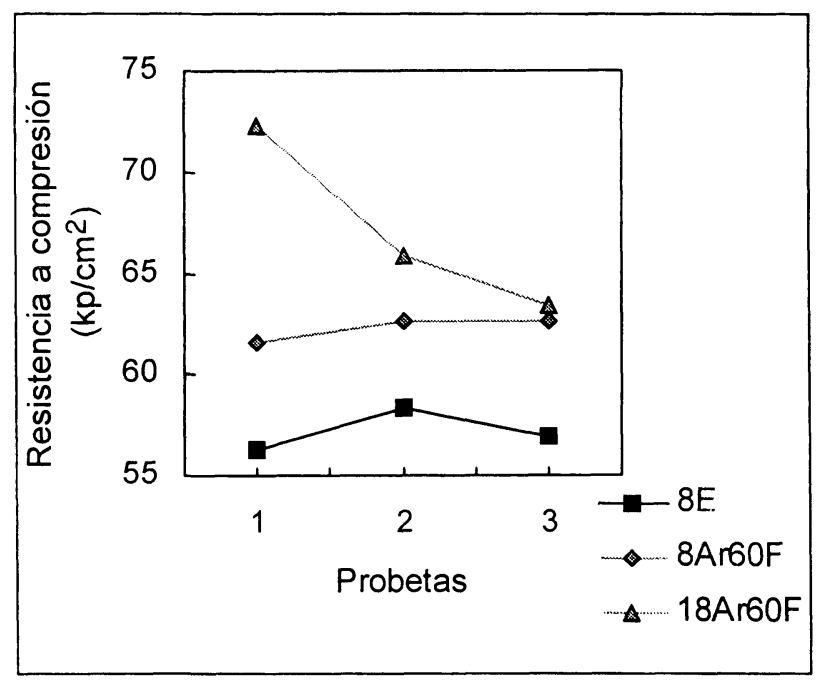

Figura 3.- Resistencia a compresión para las dos series de probetas de escayola y arcilla expandida, sin fibra de vidrio y con fibra de vidrio (1\%) $y$ de la escayola sin aditivar.

1.1.4. Conclusiones sobre la adición de arcilla expandida como aligerante en la escayola

Se considera favorable la adición de arcilla expandida en la escayola, a fin de conseguir productos prefabricados parecidos a los existentes en el mercado de escayola, con un peso menor y unas prestaciones mecánicas similares.

Se recomienda una relación agua/escayola $(\mathrm{A} / \mathrm{E})$ de 0,8 y la incorporación de fibra de vidrio $\mathrm{E}$, en un porcentaje del $1 \%$, así como añadir un $0,5 \%$ de Melment, para conseguir mejorar los valores de resistencia mecánica.

\subsection{PERLITA}

\subsubsection{Origen}

Es un silicato de origen volcánico que contiene agua de cristalización en la molécula. Este mineral, debidamente triturado a una granulometría preestablecida, se lleva a fusión sobre los 1.000 ó $1.300^{\circ} \mathrm{C}$ en hornos especiales.

A dicha temperatura el agua de cristalización se transforma en vapor y obra como expandente, hasta constituir un gránulo ligero, formado por microceldas cerradas, con un volumen hasta veinte veces superior al inicial. De ello resulta un excelente material de aislamiento térmico y acústico, utilizado tal cual en el relleno de dobles paredes o en mezcla con cementantes (cemento, yeso o escayola). Se aplica manualmente -o proyectado o gunitado- en paredes y para proteger del fuego las estructuras metálicas (protección antifuego de una hora por cada $\mathrm{cm}$ de espesor de recubrimiento). Es incombustible, por su alto punto de fusión, e imputrescible por su naturaleza mineral (4).

Hay en el mercado un producto, patentado con el nombre de PERALIT-C, para aglutinados de perlita y yeso, resistentes al fuego y antiacústicos, además reduce las humedades por condensación y la conductividad térmica en un $30 \%$.

\subsubsection{Plan de ensayos}

Se realizan tres series, para comprobar si existe compatibilidad entre el yeso y el árido, así como para analizar el material compuesto resultante a efectos de su estabilidad en el tiempo.

Estas tres series se realizan con los tres tipos de perlita más usuales en la construcción de prefabricados, en principio, además se añaden los mismos porcentajes de árido con respecto a la escayola (Tabla 2).

El tipo de perlita utilizado es:

B-10: 0-3mm. Densidad 105-125 kg/m³.

B-6: $0-1,5 \mathrm{~mm}$. Densidad $55-65 \mathrm{~kg} / \mathrm{m}^{3}$.

B-12: 0-5mm. Densidad 105-125 kg/m³.

\subsubsection{Conclusiones}

Se mezcla bien -aunque de forma manual-para que quede distribuida homogéneamente. Quedan los granos de 


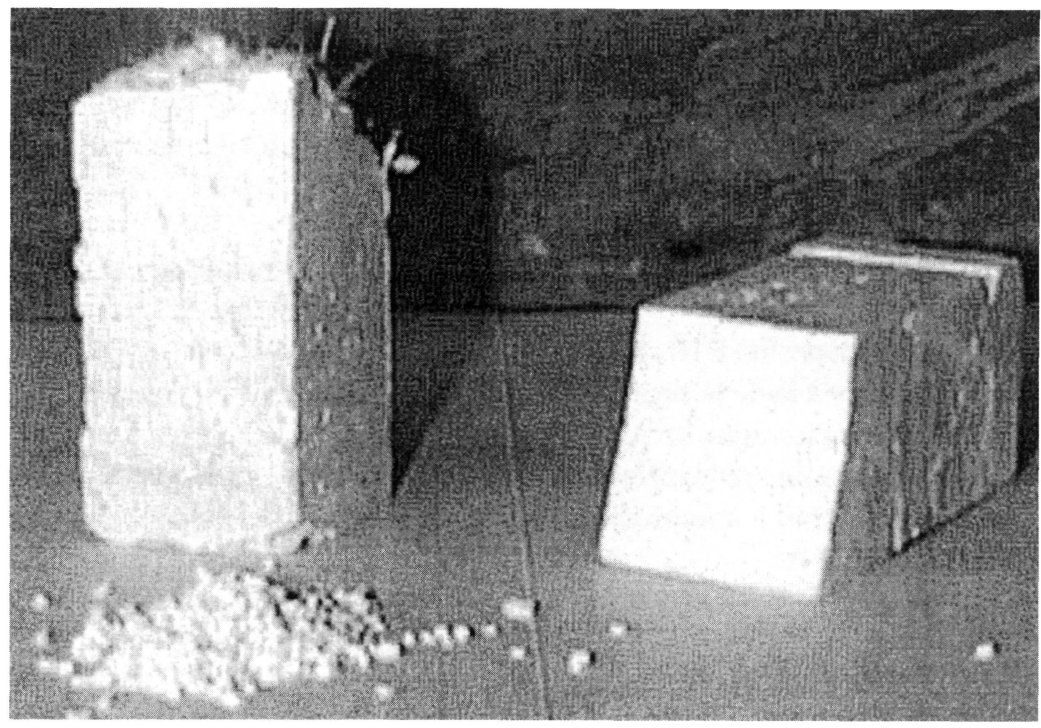

Perlita

TABLA2

\begin{tabular}{||l|l|l|l|l|l||}
\hline Serie & Tipo E & A/E & Tipo perlita & $\%$ perlita & Denominación \\
\hline 1 & E-35 & 0.8 & B-10 & 20 & 8P20B10 \\
\hline 2 & E-35 & 0.8 & B-6 & 10 & 8P20B6 \\
\hline 3 & E-35 & 0.8 & B-12 & 20 & 8P20B12 \\
\hline
\end{tabular}

perlita perfectamente integrados en la pasta de escayola, formando una masa en la que no se distinguen las partículas de perlita. Se hace necesario un compactado para asegurar el relleno total del molde. A pesar de todo, en ocasiones, las caras de las probetas presentan las superficies con pequeñas coqueras.

Las probetas de la serie 2 no admitieron un $20 \%$ de perlita B6, ya que este tipo de perlita es de menor densidad que las anteriores, reduciéndose el porcentaje al $10 \%$.
Peso

En los compuestos realizados se produce una reducción del peso de entre un 14 y un $24 \%$, del primero, al $7^{\circ}$ día. En el caso más favorable -escayola aditivada con el $20 \%$ de perlita B 10- se produce una reducción de peso, con respecto al de la escayola sin aditivos, en un $24 \%$.

\section{Rotura}

La superficie de la línea de fractura aparece con peque-

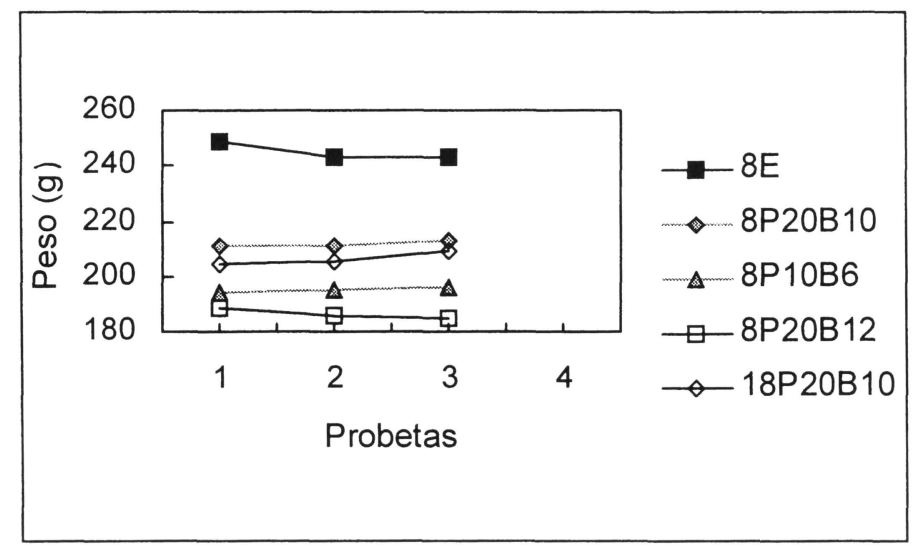

Figura 4.- Pesos de las dos series de probetas de escayola y perlita y de la escayola sin aditivar. 
ñas oquedades, debiéndose a que, al no resultar suficiente la adherencia perlita-escayola, ésta se desprende, dando lugar a la rotura. No aparecen granos de perlita rotos y la rotura de la probeta se produce casi de forma perpendiculary muy limpia, con pelo pequeño, por falta de adherencia.

\section{Resistencia mecánica}

Excepto en el compuesto realizado con perlita B10, donde la resistencia a compresión es superior a la de la escayola sin aditivary realizada con la misma relación agua/escayola (A/E) que el compuesto, en el resto disminuye la resistencia mecánica, tanto a flexotracción como a compresión, tal y como se aprecia en las figuras 5 y 6 .
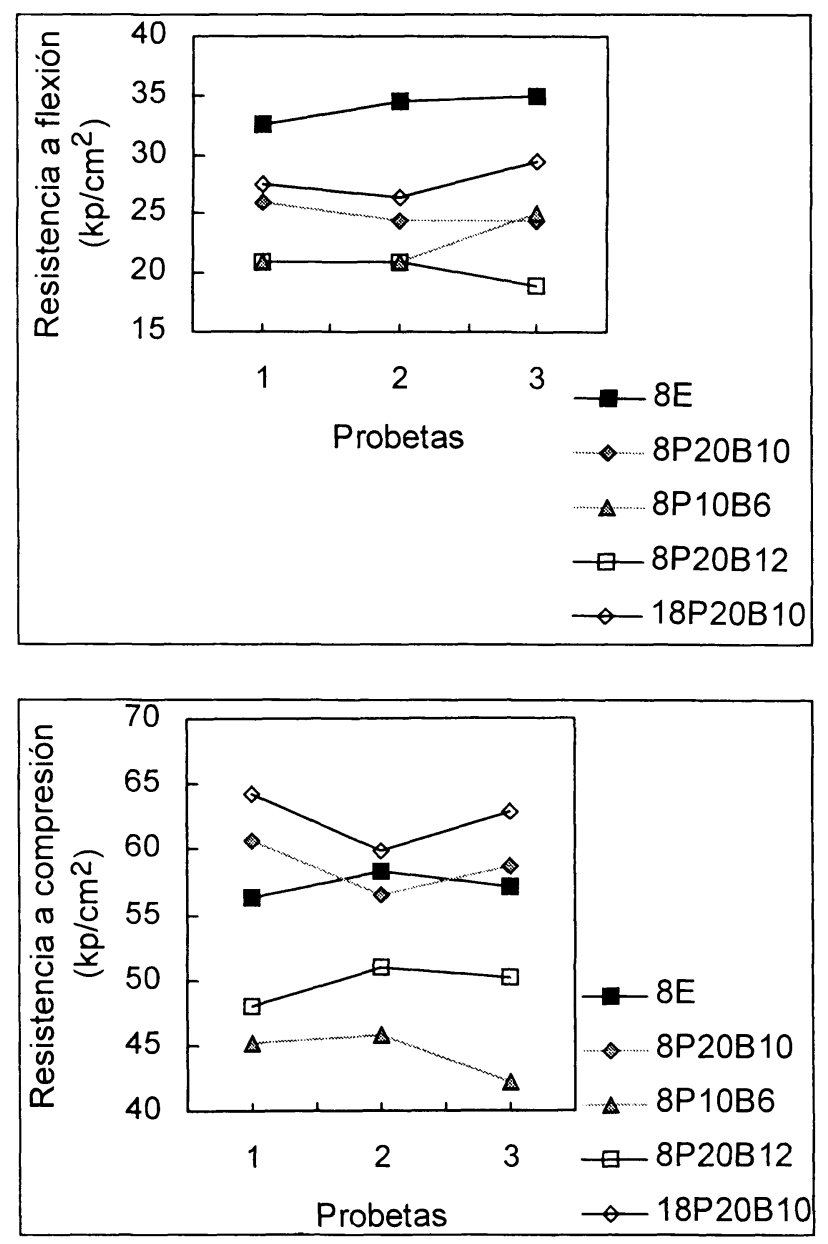

Figuras 5 y 6.- Resistencia a flexión y compresión para las dos series de probetas de escayola y perlita, con y sin fibra de vidrio y de la escayola sin aditivar.

\section{Dureza Shore C}

Es bastante regular y se mantiene en un rango similar a la de la escayola realizada con una relación agua/escayola (A/E) de 0,8 .

A la vista de los resultados se realiza una nueva serie de tres probetas con perlita B10, a la que se le añaden fibras de vidrio $\mathrm{E}$, de $25 \mathrm{~mm}$ de longitud, para comprobar si mejora la resistencia mecánica del compuesto (Tabla 3 ).

Los resultados de los ensayos de resistencia mecánica realizados sobre las probetas quedan reflejados en las figuras anteriores, para poder, así, compararlos con los valores de resistencia y peso de las probetas de escayola con perlita sin fibra de vidrio $\mathrm{E}$.

Podemos concluir diciendo que se mejora la resistencia mecánica al añadir un pequeño porcentaje de fibra de vidrio como refuerzo.

1.2.4. Conclusiones sobre la adición de perlita como aligerante en la escayola

Para una reducción de peso a tener en cuenta, la resistencia mecánica a flexión disminuye mucho en todos los compuestos, mientras que la resistencia a compresión aumenta, con un menor peso, en el compuesto 8P20B10 (escayola con relación agua/escayola (A/E) de 0,8 , aligerada con un $20 \%$ de perlita tipo B10, en el $18 \mathrm{P} 20 \mathrm{~B} 10$, lo mismo, pero con $1 \%$ de fibra de vidrio.

\subsection{VERMICULITA}

\subsubsection{Composición}

Es un mineral de la familia de la mica, compuesto, básicamente, por silicatos de aluminio, hierro y magnesio. A base de un tratamiento térmicamente controlado, a temperaturas del orden de los $700{ }^{\circ} \mathrm{C}$, el mineral se expande, exfoliándose y aumentando su volumen inicial de 20 a 30 veces. En este proceso térmico se originan, en el interior del mineral, entre sus paredes, una extraordinaria cantidad de células microscópicas cerradas, conteniendo aire, inmóvil y deshidratado.

Su estado físico es el de un sólido granulado, de fino a grueso, con un diámetro máximo de $8 \mathrm{~mm}$, de color dorado, inodoro e insoluble en agua.

TABLA3

\begin{tabular}{|l|l|l|l|l|l||}
\hline Serie & tipo E & A/E & $\%$ Perlita & $\%$ Fivi & Denominación \\
\hline 4 & E-35 & 0.8 & $20 \%$ B10 & 1 & 18 P20B10 \\
\hline
\end{tabular}


Informes de la Construcción, Vol. 50 n 458, noviembre/diciembre 1998

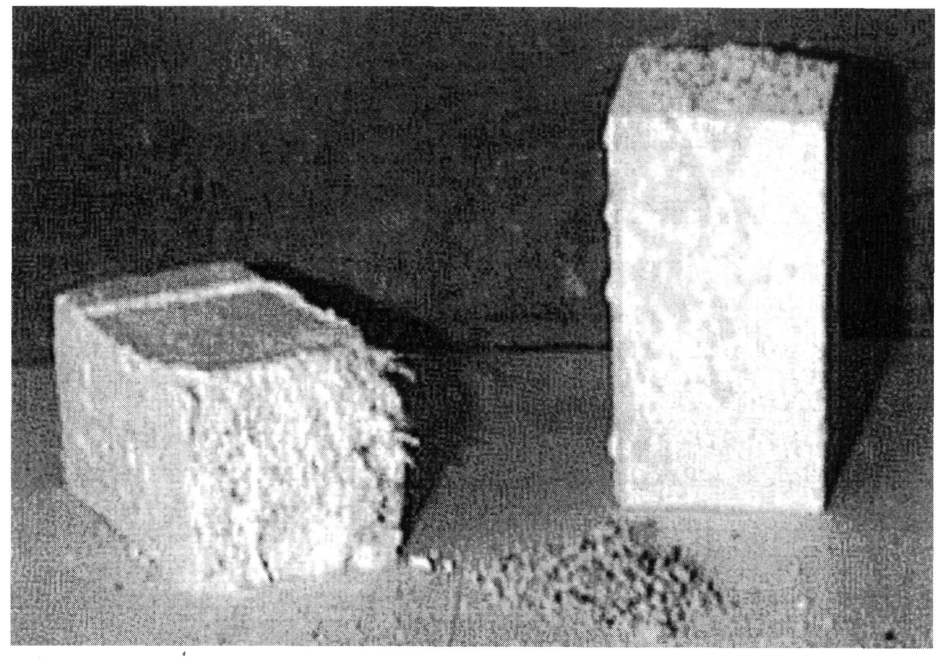

Vermiculita.

Sus principales características son: ligereza, las densidades aparentes de la vermiculita expandida oscilan entre 60 y $149 \mathrm{~kg} / \mathrm{m}^{3}$, según granulometrías.

Capacidad de aislamiento entre $-200^{\circ} \mathrm{C}$ y $1.200^{\circ} \mathrm{C} . \mathrm{Su}$ conductividad térmica es de $0,053 \mathrm{kcal} / \mathrm{h} \mathrm{m}{ }^{\circ} \mathrm{C}$ para una temperatura media de $20^{\circ} \mathrm{C}$.

Con el aumento de la temperatura, el coeficiente aumenta como en cualquier material aislante, pero con una proporción mucho menor, convirtiéndose, este material, en el aislante ideal para altas temperaturas.

Aislamiento acústico importante, así como su capacidad de absorción acústica, en una amplia gama de frecuencias.

Por su punto de fusión $1.370^{\circ} \mathrm{C}$ es un material idóneo para protecciones contra el fuego.

Es insensible a los agentes atmosféricos y al paso del tiempo. Es estable, químicamente neutra $(\mathrm{pH}=7,2)$ e inerte, no es higroscópica y no produce ninguna acción sobre el hierro o acero.

Sus aplicaciones más frecuentes en la construcción son en el campo de los aislamientos, tanto térmicos como acústicos, generalmente utilizada a granel o mezclada en revocos y en hormigones, como aligerante y protección contra el fuego.

En cuanto a sus aplicaciones con yeso, existen en el mercado productos premezclados de yeso y vermiculita que se pueden aplicar de forma manual o mediante proyección con máquina. Estos productos se aplican sobre superficies de paredes, techos y estructura.

También se puede añadir vermiculita exfoliada en el yeso de guarnecer y enlucir directamente en la obra, sin estar el producto premezclado. Para un guarnecido se recomiendan de 1 a 2 volúmenes de vermiculita, de grano fino o superfino, por un volumen de pasta de yeso. En el yeso de enlucir, un volumen de vermiculita de grano superfino por tres volúmenes de pasta de yeso (5).

\subsubsection{Plan de ensayos}

Se realizan cuatro series de probetas prismáticas, analizando las siguientes variables:

El tipo de vermiculita utilizado ha sido E-1, con una granulometría de 0,5 a $2 \mathrm{~mm}$ y una densidad que oscila entre $100-120 \mathrm{~kg} / \mathrm{m}^{3}$ y E-2, con granulometría de 0,5 a $3 \mathrm{~mm}$ y una densidad de $85-105 \mathrm{~kg} / \mathrm{m}^{3}$ (Tabla 4).

TABLA 4

\begin{tabular}{|l|l|l|l|l|l|l||}
\hline \hline Serie & Tipo E & A/E & $\begin{array}{l}\text { Tipo y } \% \\
\text { vermiculita }\end{array}$ & $\begin{array}{l}\% \\
\text { Melment }\end{array}$ & \%Fivi & Denomin. \\
\hline 1 & E-35 & 0.8 & $20 \% E 1$ & & & $8 \mathrm{~V} 20$ \\
\hline 2 & E-35 & 0.8 & $20 \% E 1$ & & 1 & $18 \mathrm{~V} 20$ \\
\hline 3 & E-35 & 0.6 & $20 \% E 2$ & $0.5 \%$ & & $6 \mathrm{~V} 20 \mathrm{M}$ \\
\hline 4 & E-35 & 0.6 & $20 \% \mathrm{E} 2$ & $0.5 \%$ & 1 & $16 \mathrm{~V} 20 \mathrm{M}$ \\
\hline
\end{tabular}




\section{Mezcla}

Se hace necesaria una mezcla manual, para conseguir homogeneidad.

Pasta poco fluida, debido a la avidez del árido, lo que dificulta el relleno de los moldes, por lo que se realiza un vibrado y compactado manual, a fin de evitar coqueras en las caras de contacto con el molde.

Cuando se añade fibra de vidrio como refuerzo en la pasta esto se agrava, debido a los apelmazamientos de la misma.

El enrase de la cara superior de la probeta es dificil, por arrastre de las fibras.

En las probetas realizadas con una relación agua/escayola $(\mathrm{A} / \mathrm{E})$ de 0,6 la mezcla es todavía más seca, pues se añade vermiculita de menos densidad y, a pesar de los procedimientos utilizados, aparecen coqueras en la superficie de las probetas.

Sobre las probetas se realizan ensayos de flexotracción, compresión y medición de la dureza Shore C.

\subsubsection{Conclusiones}

\section{Peso}

El peso, para una relación agua/escayola (A/E) de 0,8 , disminuye casi un $15 \%$ frente al peso de la escayola sin aditivar.

Para una relación agua/escayola $(\mathrm{A} / \mathrm{E})$ de 0,6 , reduce el peso frente a la escayola sin aditivar con la misma relación agua/escayola (A/E) en un 16\%.

\section{Rotura}

A pesar de ser casi perpendicular se producen pequeñas crestas y valles, buscando las zonas más débiles (escayola sola).

Cuando se añade fibra en la pasta no hay separación de las dos partes en que queda dividida la probeta, pues las fibras las unen.

Además, la superficie de fractura es más irregular, dependiendo de la uniformidad en el reparto de la fibra, el pelo de fractura es más grueso.

Si la zona de fractura coincide con la acumulación de fibras aparecen crestas.

\section{Resistencia a flexotracción}

Los resultados siempre están por debajo de los resultados obtenidos en las probetas de escayola sin aditivar, en un $26,8 \%$.

Este porcentaje disminuye un poco si se añade un $1 \%$ de fibra de vidrio $\mathrm{E}$ de $25 \mathrm{~mm}$ de longitud.

A su vez, los valores de resistencia a flexotracción de la escayola sin aditivary realizada con una relación de $\mathrm{A} / \mathrm{E}$ de 0,8 se superan en las probetas confeccionadas con un $20 \%$ de perlita frente al peso de la escayola y realizadas con una relación agua/escayola $(\mathrm{A} / \mathrm{E})$ de 0,6 , con un $0,5 \%$ de dispersión polimérica Melment. El inconveniente es el aumento de peso del material compuesto definido.

\section{Resistencia a compresión}

Los resultados siempre están por debajo de aquéllos

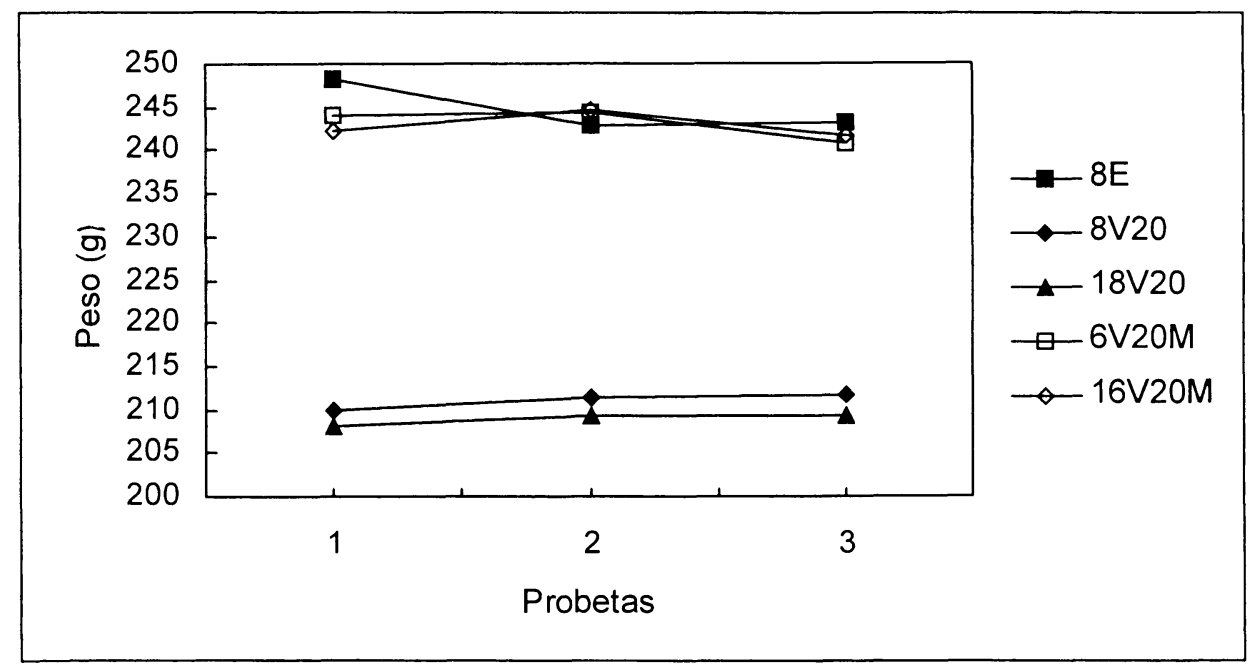

Figura 7. - Pesos de probetas de escayola y vermiculita, con y sin fibra de vidrio y de la escayola sin aditivar 


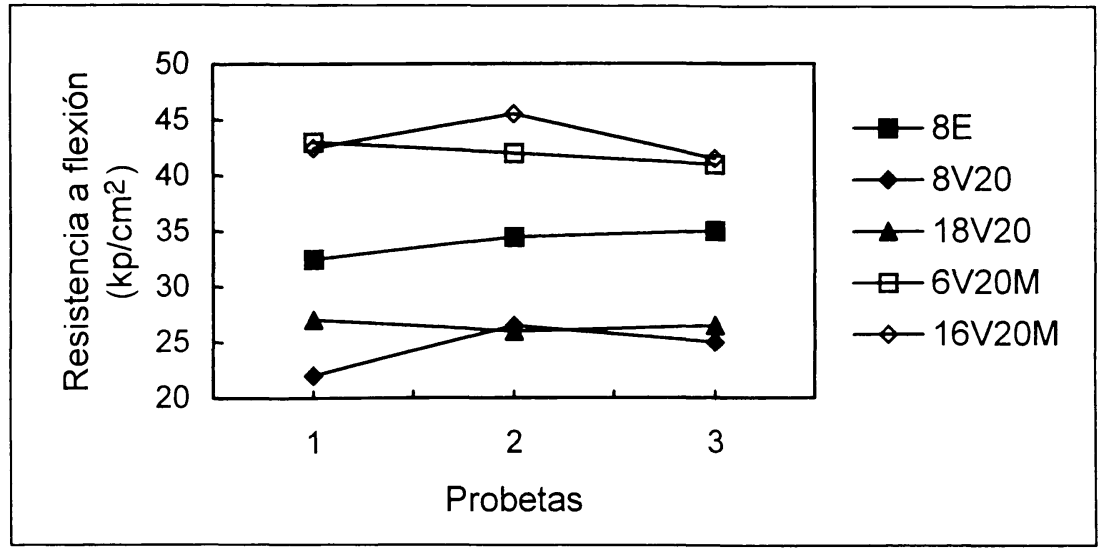

Figura 8.- Resistencia a flexión para las series de probetas de escayola y vermiculita, con y sin fibra de vidrio y de la escayola sin aditivar.

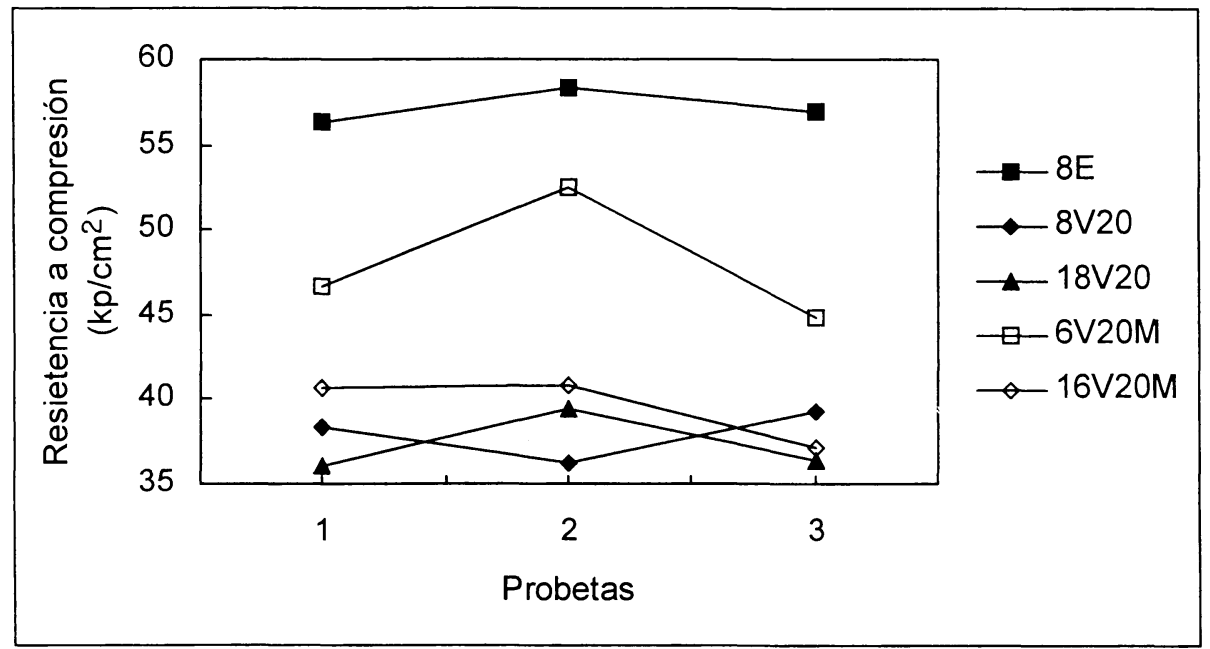

Figura 9.- Resistencia a compresión para las series de probetas de escayola y vermiculita, con y sin fibra de vidrio y de la escayola sin aditivar.

obtenidos en las probetas de escayola sin aditivar, en un porcentaje de un $33,8 \%$ para el compuesto $8 \mathrm{~V} 20$.

El añadir fibra de vidrio no supone ninguna mejora.

\section{Dureza Shore C}

Los resultados son menores que los obtenidos en las probetas de escayola sin aditivar.

1.3.4. Conclusiones sobre la adición de vermiculita como aligerante en la escayola

La adición de vermiculita en la escayola es, para un porcentaje del $20 \%$ de perlita sobre el peso de la escayola, una reducción poco importante del peso y una disminución de la resistencia mecánica y la dureza Shore C. Esta situación no es más favorable al añadir fibra de vidrio $\mathrm{E}$, ni al reducir la relación agua/escayola $(\mathrm{A} / \mathrm{E})$ e incorporar Melment en la matriz, ya que se incrementa considerablemente el peso del material.

\section{ADICIÓN A LA ESCAYOLA DE GRANULADOS DEMATERIALESLIGEROS}

Se propone la realización de probetas prismáticas de escayola aligeradas mediante granulados ligeros.

Dentro de estos granulados, se clasifican, para la realización del material compuesto escayola+material ligero granulado, los más frecuentes de encontrar en el mercado de la construcción española:

. Poliestireno expandido

. Corcho 


\subsection{POLIESTIRENOEXPANDIDO}

\subsubsection{Tipo de material}

Material plástico celular y rígido, fabricado a partir del moldeo de perlas preexpandidas de poliestireno expandible o uno de sus copolímeros, que presenta una estructura celular cerrada y rellena de aire.

Material de gran resistencia térmica, aunque ésta va a depender de la densidad del material y, por tanto, de su proceso de fabricación.

Bajo valor de absorción de agua, oscilando entre el 0,5\% y el $3 \%$ en volumen.

En el caso de combustión, al estar constituido en un $98 \%$ por aire, las emisiones de gases son moderadas, componiéndose, fundamentalmente, de dióxido de carbono y vapor de agua.

Es imputrescible y mantiene sus propiedades en el tiempo.

Compatible con los materiales habituales de construcción, pero mala resistencia frente a los disolventes orgánicos.

Es ecológico, ya que no contiene CFC s ni HCFC s, es inerte y no tóxico, no liberando sustancias nocivas.
Su principal aplicación en construcción es en el campo de los aislamientos térmicos, fundamentalmente para cámaras de aire y en cubiertas. Se utiliza en forma de granulado y en formato de panel rígido (6).

En cuanto a sus aplicaciones con el yeso, lo habitual es encontrarlo como trasdosado, desde la forma de paneles de poliestireno expandido o extruido, a placas de yeso laminado o yeso fibra; el producto final, dependiendo de la firma comercial que lo confeccione, se denomina de diferentes maneras.

\subsubsection{Plan de ensayos}

En un primer tanteo se busca el porcentaje máximo, sobre el peso de la escayola, del poliestireno expandido a incorporar a la escayola: permite una reducción de la densidad del material compuesto resultante y una posible trabajabilidad de la mezcla.

De los resultados obtenidos se concluye que se debe trabajar con un porcentaje máximo del $3 \%$ de poliestireno sobre el peso de la escayola.

Además, el tipo de granulometría recomendada está entre 4 y $8 \mathrm{~mm}$.

Por otra parte, como los resultados de los ensayos de resistencia mecánica sobre probetas confeccionadas con

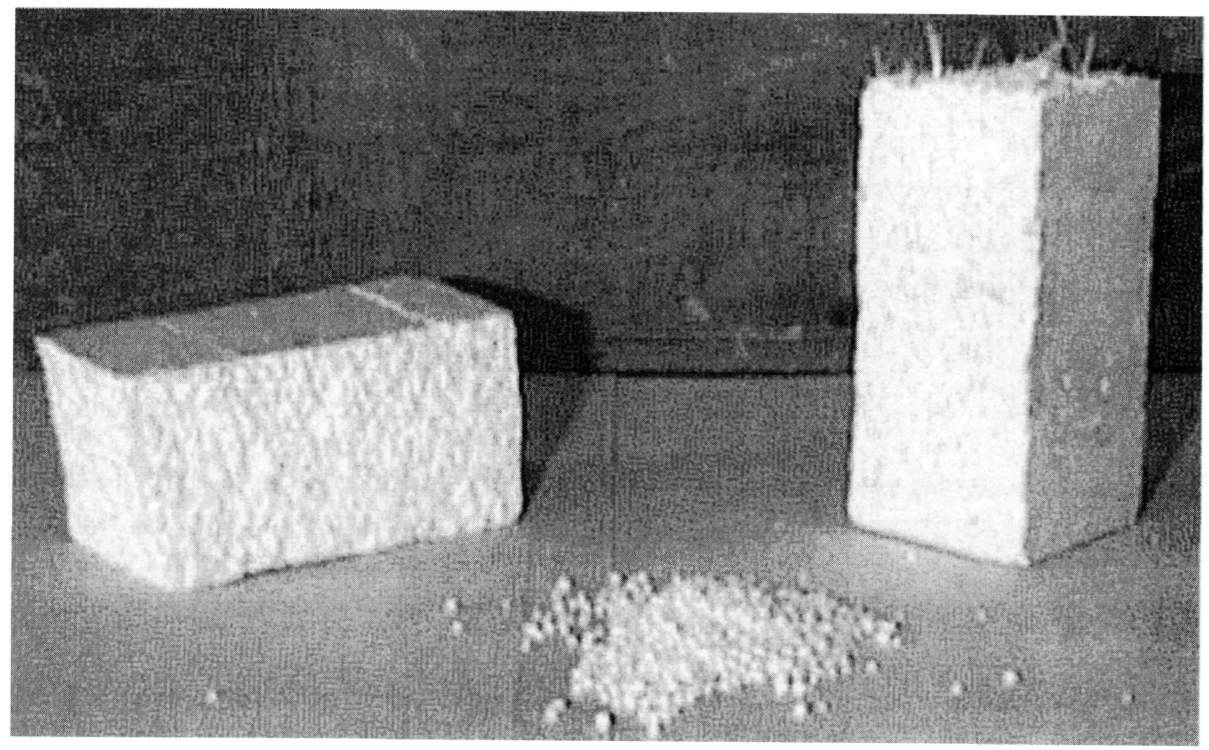

Poliestireno expandido.

TABLA5

\begin{tabular}{|l|l|l|l|l|l|l||}
\hline Serie & Tipo E & A/E & $\begin{array}{l}\text { Tipo y } \% \\
\text { poliestireno }\end{array}$ & $\%$ Fivi & $\%$ Melment & Denomin. \\
\hline 10 & E-35 & 0.6 & $3 \% 4 y 8 m m$ & 1 & 0.5 & 16 Po3M \\
\hline 11 & E-35 & 0.6 & $3 \% 4 y 8 m m$ & 2 & 0.5 & 26Po3M \\
\hline
\end{tabular}


escayola con relación agua/escayola $(\mathrm{A} / \mathrm{E})$ de 0,8 y un $3 \%$ de poliestireno han sido muy deficientes, se recomienda trabajar con una relación de agua/escayola $(\mathrm{A} / \mathrm{E})$ menor $(0,6)$, a la que se añadirán fibras de vidrio $\mathrm{E}$ de $25 \mathrm{~mm}$ de longitud y un $0,5 \%$ de Melment para mejorar la trabajabilidad, habida cuenta la electricidad estática del poliestireno y la falta de adherencia del mismo con la escayola (Tabla 5).

Sobre estas probetas se realizan ensayos de resistencia mecánica y se toman medidas de la dureza Shore C.

\subsubsection{Conclusiones}

Mezcla

La mezcla se realiza con un amasado conjunto de la escayola y los granos de poliestireno, impidiendo la flotación de los mismos, añadiendo peso a la probeta. Se realiza además un vibrado y una compactación para evitar coqueras en las probetas.

El enrasado resulta difícil por el arrastre de fibras y granos.

Peso

La pérdida de peso, a los siete días, es de un $27 \%$ aproximadamente.

La reducción de peso con respecto a la escayola sin aditivar es de un $40 \%$ aproximadamente, lo que resulta muy interesante. Incluso si tomamos como referencia la escayola, con una relación de agua/escayola $(\mathrm{A} / \mathrm{E})$ igual a 0,6, llega, esta reducción, a suponer casi un $50 \%$.

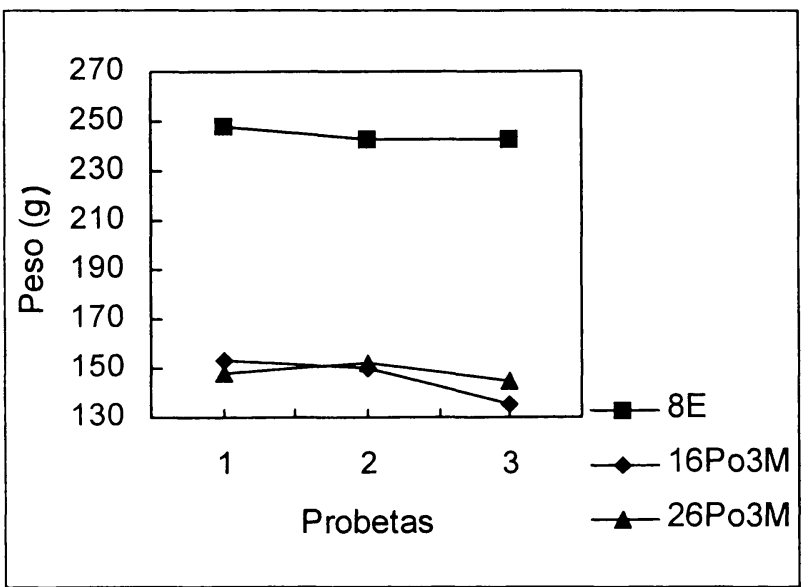

Figura 10.- Pesos de las series de probetas de escayola-poliestireno expandido reforzadas con fibras de vidrio y de la escayola sin aditivar.

\section{Rotura}

La falta de adherencia entre la escayola y los granos de poliestireno se constata al observar cómo ninguno de los granos se ha roto y en las dos partes de la superficie de rotura aparecen los granos desprendidos

Se produce una fisura perpendicular con formación de valles y crestas, señalados por zonas de acumulación de granos y fibra. Cuanto menos homogénea es la probeta más irregular es la fisura.

No se produce el desprendimiento de las dos partes en que queda dividida la probeta por la acción de las fibras.

Debido a la de Melment aumenta mucho la tenacidad del material y, en ocasiones, la probeta rompe en multitud de fisuras, en vez de en una única .

\section{Resistencia mecánica}

Como hemos venido comprobando, una reducción importante de peso se asocia, siempre, a una disminución de la resistencia mecánica del material.

\section{Flexotracción}

Frente a una pérdida de resistencia a flexión, con respecto a la escayola sin aditivar de aproximadamente un $70 \%$, al reducir el agua y añadir fluidificante esta pérdida se reduce al $50 \%$.

Con la adición del doble de fibra se reduce este porcentaje, quedando en un $45 \%$.

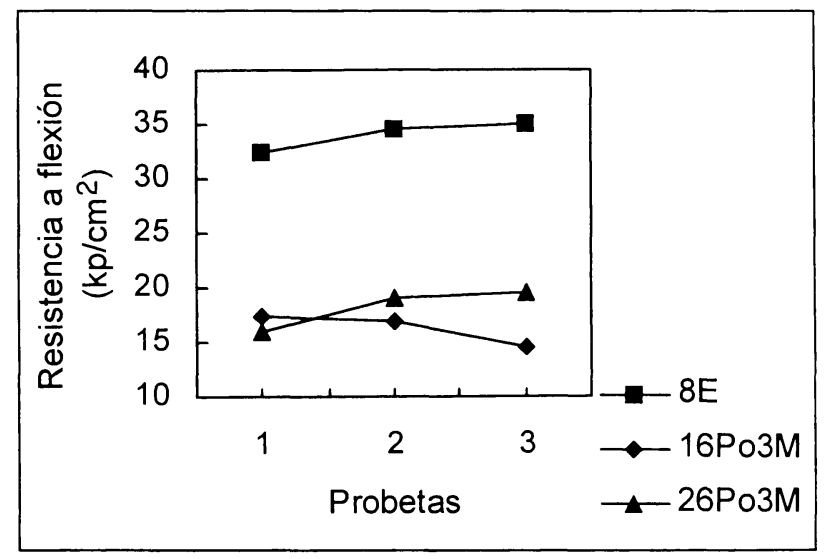

Figura 11.- Resistencia a flexión de las series de probetas de escayolapoliestireno expandido reforzadas con fibras de vidrio y de la escayola sin aditivar. 


\section{Compresión}

La pérdida de resistencia a compresión con respecto a la escayola sin aditivar es de aproximadamente un $57 \%$.

Lo que significa un aumento de la resistencia de un $10 \%$, al disminuir la relación $\mathrm{A} / \mathrm{E}$ y añadir una pequeña cantidad de fluidificante.

El aumentar al 2\% la fibra de vidrio no mejora estos valores.

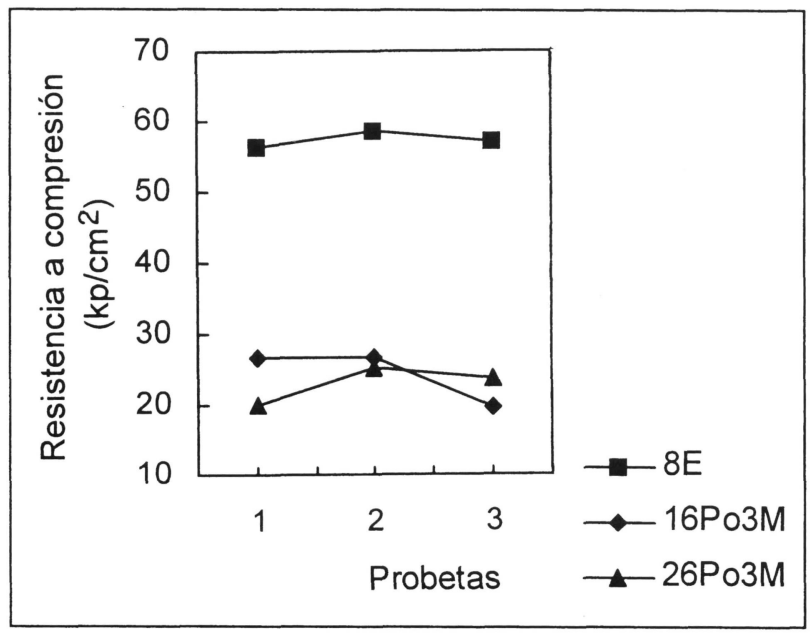

Figura 12.- Resistencia a compresión de las series de probetas de escayola-poliestireno expandido reforzadas con fibras de vidrio y de la escayola sin aditivar.

\section{Dureza Shore C}

Los valores de dureza son poco constantes, ya que depende de si el durómetro se coloca contra un grano de poliestireno o la escayola.

2.1.4. Conclusiones sobre la adición de gránulos de poliestireno expandido como aligerante en la escayola

Con la adición de poliestireno en la escayola se consiguen grandes reducciones de peso frente a la escayola sin aditivar, la contrapartida es que al no haber adherencia entre los granos de poliestireno y la escayola se necesita un gran refuerzo de la matriz mediante fibras de vidrio, $u$ otras, para lograr un aumento de la tenacidad del material compuesto, así como una mejora de sus prestaciones mecánicas y, de esta forma, poder ser competitivo con los productos prefabricados de escayola que existen actualmente en el mercado.

\section{2. $\mathrm{CORCHO}$}

\subsubsection{Material}

Revestimiento del tronco y las ramas del alcornoque (Quercus Suber.) (7).

El corcho es un tejido vegetal, constituido por la agrupación de células muertas y con forma, estructura y disposición particulares.

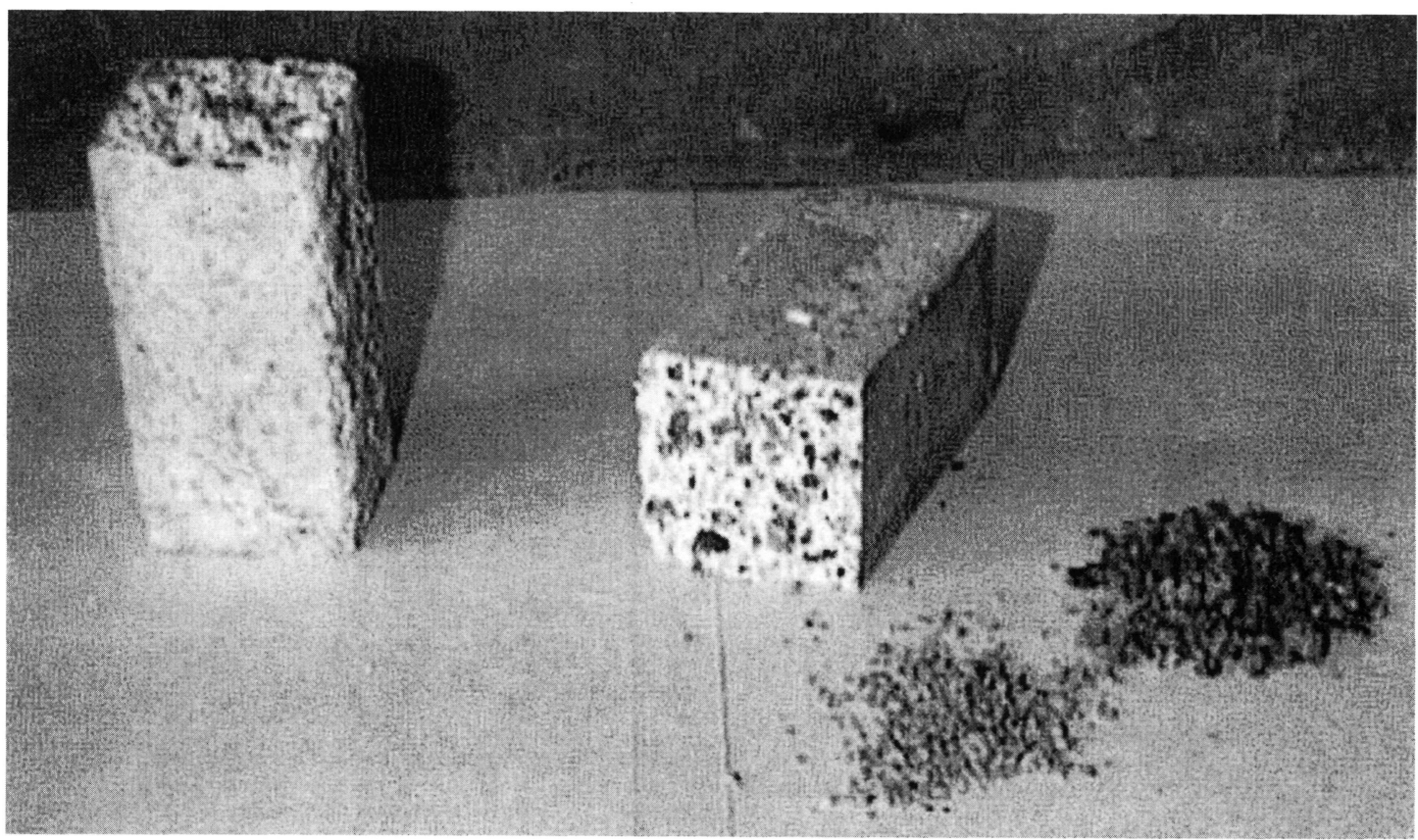

Corcho. 
Las celdas de corcho poseen 14 caras, seis de ellas son cuadriláteros y ocho de ellas hexágonos. Ésta es la forma más perfecta que ofrece la naturaleza para conseguir el mayor volumen con la mínima superficie.

El número de celdas por centímetro cúbico es del orden de millones.

Las células que constituyen el corcho están dispuestas muy regularmente y próximas entre sí, sin que existan espacios intercelulares.

Cada célula está formada por una cámara de aire, envuelta por una membrana o pared celular.

Las aplicaciones del corcho en la construcción de edificios han sido, a lo largo del tiempo, muy variadas, p.e. como material aislante en suelos y tejados, como relleno de juntas..., etc. Pero es a partir de la realización de aglomerados de corcho cuando se empieza a comercializar masivamente, generalmente para revestimientos de suelos y paredes, por su alta capacidad de absorción acústica al ruido aéreo e impacto (8).

En cuanto a la utilización del corcho como aditivo para el yeso o la escayola, hemos encontrado una referencia bibliográfica (9) que describe cómo en los comienzos de la industria del corcho aglomerado y después de realizar éstos con colas orgánicas y no habiendo obtenido buenos resultados, se busca en los minerales, entre los que se encuentra el yeso, el aglutinante que se necesitaba. Al ser éste bastante denso, resultaban aglomerados muy pesados, desechándose, por tanto, esta solución de material compuesto.

Para la realización del estudio se utilizan los siguientes tipos de corcho:

DESECHOS ENFORMA DE GRANULADO (partículas de corcho de granulometría entre $0,25 / 0,45 \mathrm{~mm}$ ) $\mathrm{Y}$ POLVO (partículas de corcho de granulometría menor de $0,25 \mathrm{~mm})$.

BORNIZO DE INVIERNO: corcho rugoso, que constituye el revestimiento de origen, normalmente de ramas podadas.

BORNIZO DE VERANO: corcho rugoso, que se obtiene de árboles en pie y que son aprovechados por primera vez.

RESTOS DE PODA: material pulverulento, se compone de madera triturada proveniente de la poda de las ramas de encina y alcornoque (serrín de madera). También lleva incorporado granos de corcho y fibras de más de $12 \mathrm{~mm}$.

\subsubsection{Plan de ensayos}

Se comienza realizando probetas prismáticas, de

(c) Consejo Superior de Investigaciones Científicas Licencia Creative Commons 3.0 España (by-nc) dimensiones $4 \times 4 \times 16 \mathrm{~cm}$, según norma con E-30 y distintos tipos de corcho en un $20 \%$, que parece lo máximo admisible, excepto en RP que tiene mayor densidad y admitiría más, tanteando las relaciones de agua/escayola $(\mathrm{A} / \mathrm{E})$ de 0,6 y 0,8 . A los 7 días de secado se rompen a flexión y a compresión.

El peso: oscila con la densidad del granulado de corcho utilizado, pero, en general, excepto en los restos de poda, se obtiene una reducción del mismo frente a probetas realizadas sólo con escayola de un $20 \%$.

\subsubsection{Conclusiones}

Resistencia a flexión: todas las probetas tienen parecidos valores de resistencia.

Las probetas no tienen una rotura frágil por separación de las dos partes en que queda dividida la fractura, sino que los granos de corcho y, más especialmente, los restos de poda, fibras...,consiguen mantener la cohesión entre las dos superficies de fractura, como si de una acción de refuerzo se tratara.

Cuando disminuye la relación agua/escayola $(\mathrm{A} / \mathrm{E})$ a 0,6 , los valores del BI mejoran muy poco, los de BRV aumentan en un $34 \%$ y la resistencia del compuesto escayola y RP, hasta un $81 \%$, frente a relaciones de agua/escayola $(\mathrm{A} / \mathrm{E})$ de 0,8 .

Lógicamente, este aumento de resistencia está acompañado de un aumento del peso de las probetas.

Resistencia a compresión: todas las probetas, excepto las de BI, alcanzan la carga de rotura cuando se rompen las caras laterales, apareciendo fisuras y abombamientos en las mismas.

Con el BI, al tener más cantidad de corcho es más elástico, no produciéndose en la probeta ni desprendimientos ni fisuras apreciables.

Los valores de resistencia a compresión son similares a los de flexión.

La disminución de la relación agua/escayola $(\mathrm{A} / \mathrm{E})$ conlleva un aumento de peso y poco aumento de la resistencia, excepto en las probetas de RP que supone un $73 \%$ de más sobre la relación agua/escayola $(\mathrm{A} / \mathrm{E})=0,8$.

Aunque la resistencia mecánica en general de estas probetas es inferior a probetas de escayola realizadas con la misma relación $(\mathrm{A} / \mathrm{E})$, se observa una mejora de la tenacidad en el producto obtenido, ya que las roturas, que se producen cuando se alcanzan las cargas últimas, aun siendo roturas frágiles por la matriz, no dan lugar a la separación brusca e instantánea en dos partes de la probeta, sino que los granulados y las fibras mantienen cosidas las dos 
superficies de rotura, impidiendo el desprendimiento repentino.

- A la vista de esto se realizan nuevas series de probetas, controlando diversas variables que, a nuestro modo de ver, pueden contribuir a mejorar la resistencia mecánica del material, posibilitando el desarrollo de un producto competitivo con los similares de yeso en el mercado, aportando, además, una reducción de peso, mejorando las características térmicas, acústicas y de seguridad ante el fuego y el impacto.

Estas variables son:

. Tipo de corcho.

- Porcentaje de corcho.

. Presión durante el fraguado.

- Adición de fibra de vidrio.

Adición de dispersiones poliméricas.

En la figura 13 se observa la influencia del tipo de corcho añadido en la resistencia mecánica del compuesto yesocorcho.
De dicha figura podemos concluir que, de los distintos granulados de corcho que se han utilizado, los que mejor relación densidad/resistencia mecánica ofrecen son BI y RP.

Ahora bien, reduciremos la cantidad de polvo de corcho para que el compuesto sea más limpio y pese menos.

Desde el punto de vista de la granulometría, comentar que las mejores prestaciones se consiguen con granos medios, de diámetro aproximado de $2,8 \mathrm{~mm}$, al que se le añade un mínimo porcentaje del $5 \%$, frente al $15 \%$ de grano de 1,0 $\mathrm{mm}$ de diámetro, como puede observarse en la figura 14

Se considera también la posibilidad de retriturar los granos, a fin de conseguir una mayor superficie de contacto entre el yeso y los granos de corcho y, por tanto, una mejora de las prestaciones mecánicas por aumento de la adherencia, pero se comprueba que no se traduce en una mejora y que continúa con la relación, ya observada, de peso/resistencia. En cuanto a la influencia del porcentaje de corcho sobre la resistencia mecánica del material compuesto yeso-corcho, comentar que se realizan probetas con un $10 \%$ de corcho añadido sobre el peso de la escayola y se

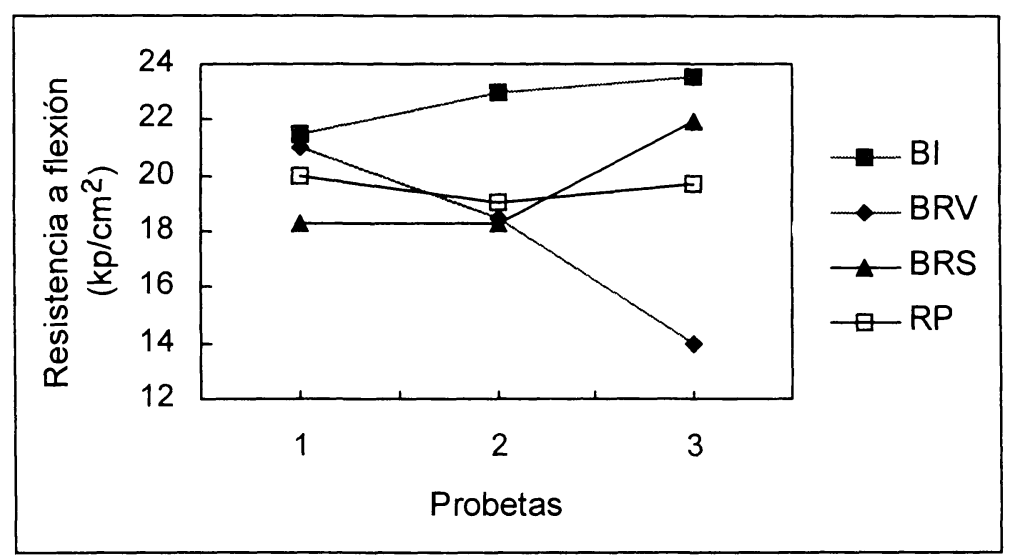

Figura 13.- Resistencia a flexión de las series de probetas ensayadas, con distinto tipo de corcho.

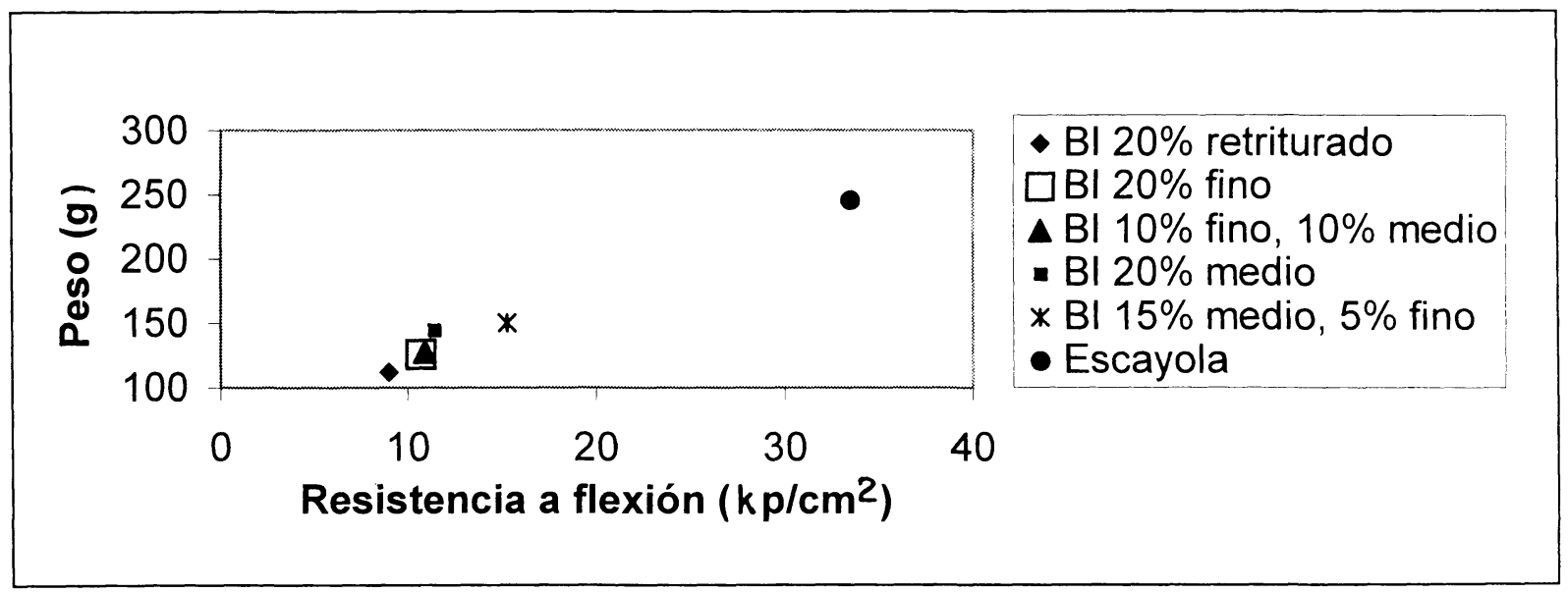

Figura 14.- Resistencia a flexión de series de probetas realizadas con distintas granulometrías y con el grano retriturado. 
ensayan a flexión y compresión. Los resultados de estos ensayos se muestran en las figuras 15 y 16 , junto con los resultados de probetas con un añadido de corcho del $20 \%$ sobre el peso de la escayola.

De la comparación de resultados con las probetas con un $20 \%$ de corcho concluimos que la disminución del porcentaje de corcho no supone una mejora considerable de las prestaciones mecánicas, pero, en cambio, el material compuesto resultante es de una densidad similar a la escayola sin adiciones.

Presión durante el fraguado: Al añadir presión a las probetas durante el fraguado se impide la flotación del granulado de corcho, consiguiendo mayor homogeneidad en el compuesto. En caso contrario la masa se disgrega, dando lugar a una probeta con una cara inferior a modo de bizcocho de escayola y una superior de corcho rugoso, pudiendo resultar una solución interesante en trasdosados.

En la figura 17 se muestran los resultados del refuerzo con fibras.

Se trabaja con fibra de vidrio $\mathrm{E}$ de $25 \mathrm{~mm}$ de longitud.

Se añade la fibra en proporción del 1 y $2 \%$ sobre el peso de la escayola.

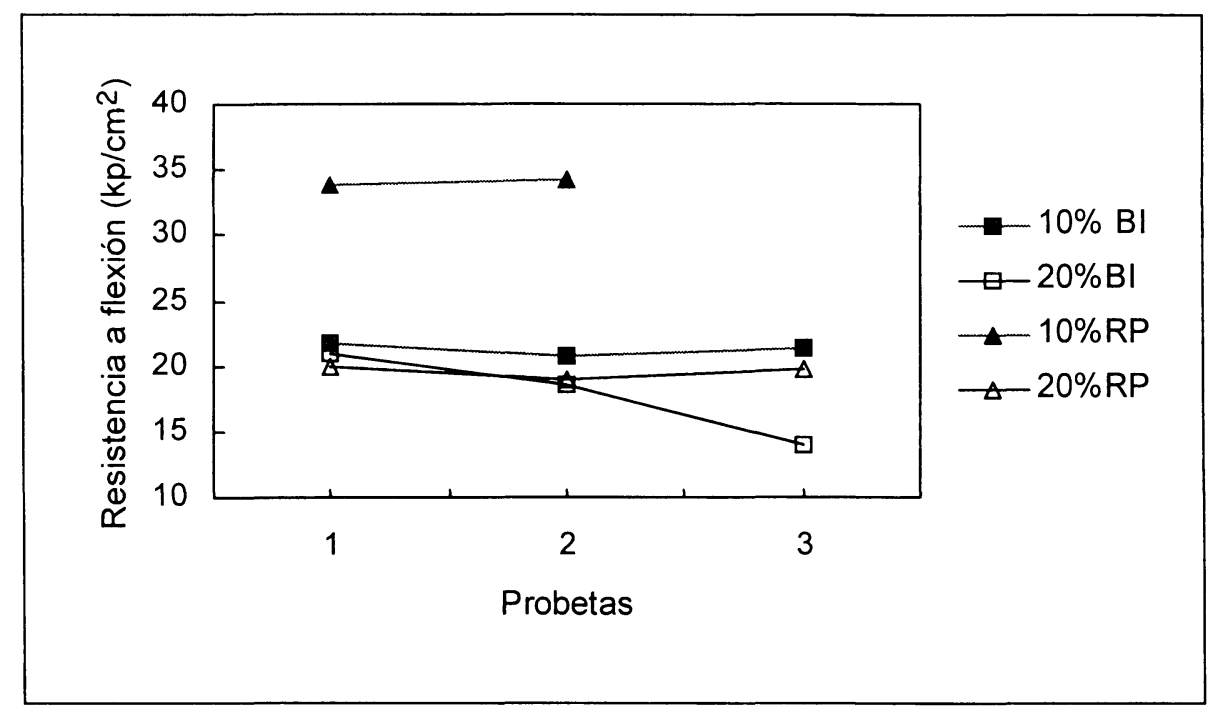

Figura 15.- Resistencia a flexión de las dos series de probetas con un porcentaje de corcho BI, añadido sobre el peso de la escayola, del $20 \%$ y del $10 \%$ y de RP del $10 \%$ y el $20 \%$.

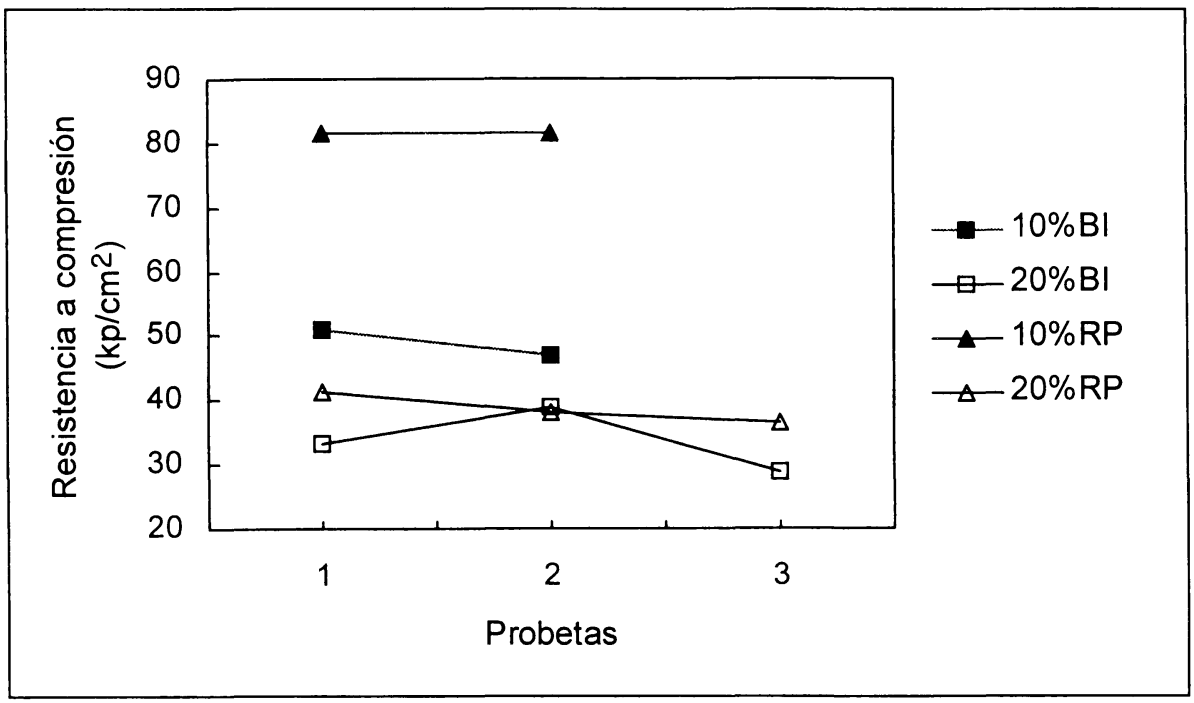

Figura 16.- Resistencia a compresión de las dos series de probetas con un porcentaje de corcho BI, añadido sobre el peso de la escayola, del $20 \%$ y del $10 \%$ y de RP del 10 y el $20 \%$. 


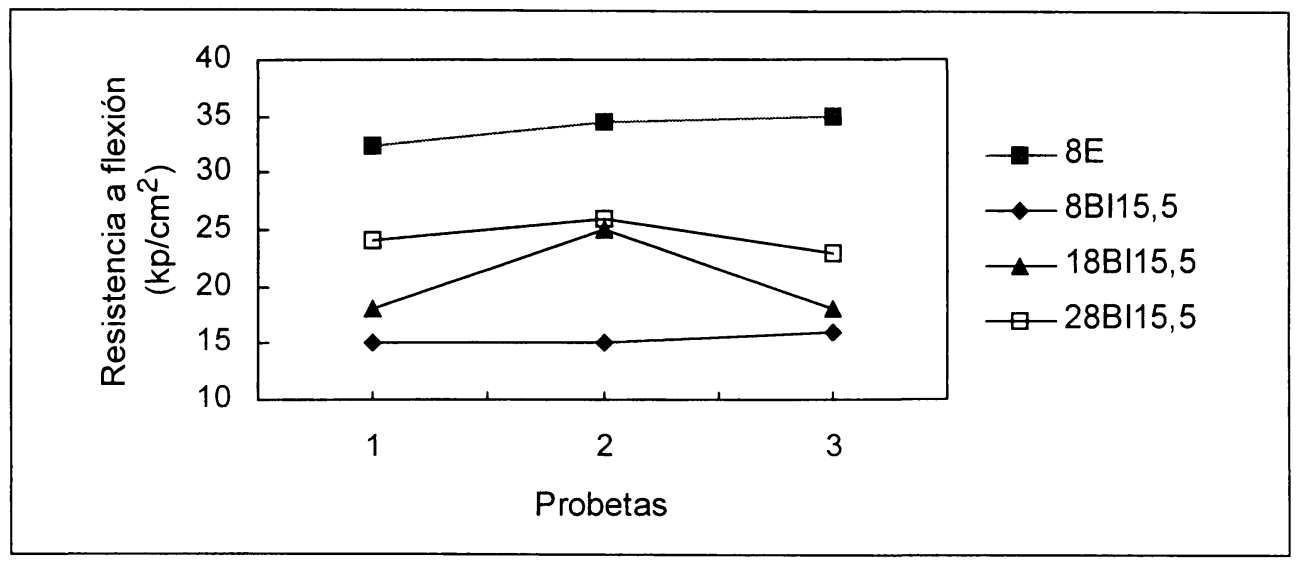

Figura 17.- Resistencia a flexión de series de probetas realizadas con BI y distintos porcentajes de fibra de vidrio.

Queda demostrado que se mejora la resistencia mecánica a flexión de las probetas al añadir fibra de vidrio. Esta mejora es mayor con un refuerzo del $2 \%$, llegando al $50 \%$ frente a probetas de escayola sin reforzar y consiguiendo mejorar la tenacidad del material e impidiendo la separación total de la superficie de fractura.

En la disposición de la fibra en la matriz parece mejor la distribución homogénea de la misma, aunque no se descarta concentrarla en dos pieles, inferior y superior, configurando un producto final tipo sandwich comparable a similares productos competitivos de núcleo de poliestireno, p.e.

En la figura 18 se observan los resultados de la adición de dispersiones poliméricas.

Se incorpora una dispersión de melamina formaldehido a la mezcla. Esta dispersión ya se ha utilizado en otros trabajos, en proporción de un $0,5 \%$ sobre el peso de la escayola, porcentaje recomendado por el fabricante. Al igual que otras veces, esta dispersión nos permite reducir el agua de amasado.

En dicha figura se observa que aumenta la resistencia mecánica del compuesto para densidades similares $\mathrm{y}$, lo que es más de destacar, en vez de aparecer una única rotura se observa una multitud de pequeñas fisuras, llegando, en alguna probeta, a no producirse -incluso después de alcanzar la carga de rotura- la separación en dos partes.

Se recomienda no disminuir la relación $\mathrm{A} / \mathrm{E}$, ya que aumenta la densidad del compuesto.

Conclusiones sobre la adición de corcho como aligerante en la escayola

Destacaríamos, como característica principal del compuesto, su baja densidad. Esta disminución de la densidad da lugar a una reducción de la resistencia mecánica del compuesto, pero se ha comprobado que se puede mejorar su resistencia mecánica, fundamentalmente a flexión, con la incorporación de fibras de vidrio $\mathrm{E}$, en un pequeño porcentaje, así como con la adición de una dispersión polimérica de melamina formaldehido.

La aplicación general de esto es la realización de productos prefabricados semejante a los existentes en el mercado, pero con pesos muy inferiores, lo que facilitaría la puesta en obra de los mismos, aumentando el rendimiento, asi como su transporte hasta la misma, disminuyendo las roturas y desconchones.

Se mejorarían además, como se ha dicho, el comportamiento acústico, térmico, etc., frente a productos similares de escayola sin aditivar.

\section{Conclusiones finales}

Se presentan una serie de figuras que pretenden resumir todo el trabajo.

En ellas se recogen los resultados más favorables de las probetas realizadas con cada tipo de carga celular ya estudiada.

\section{Peso}

En la figura 19 se recogen los pesos de las probetas de escayola aligerada con diferentes cargas celulares.

La diferenciación entre los dos grupos de sólidos celulares que se hace al principio del trabajo se mantiene.

En el grupo de áridos ligeros propuesto (arcilla expandi$\mathrm{da}$, perlita y vermiculita) se consiguen reducciones de peso en las probetas del orden de un $20 \%$, en el mejor de los casos, frente a probetas de escayola, de la misma relación agua/escayola, pero sin aligerar. 


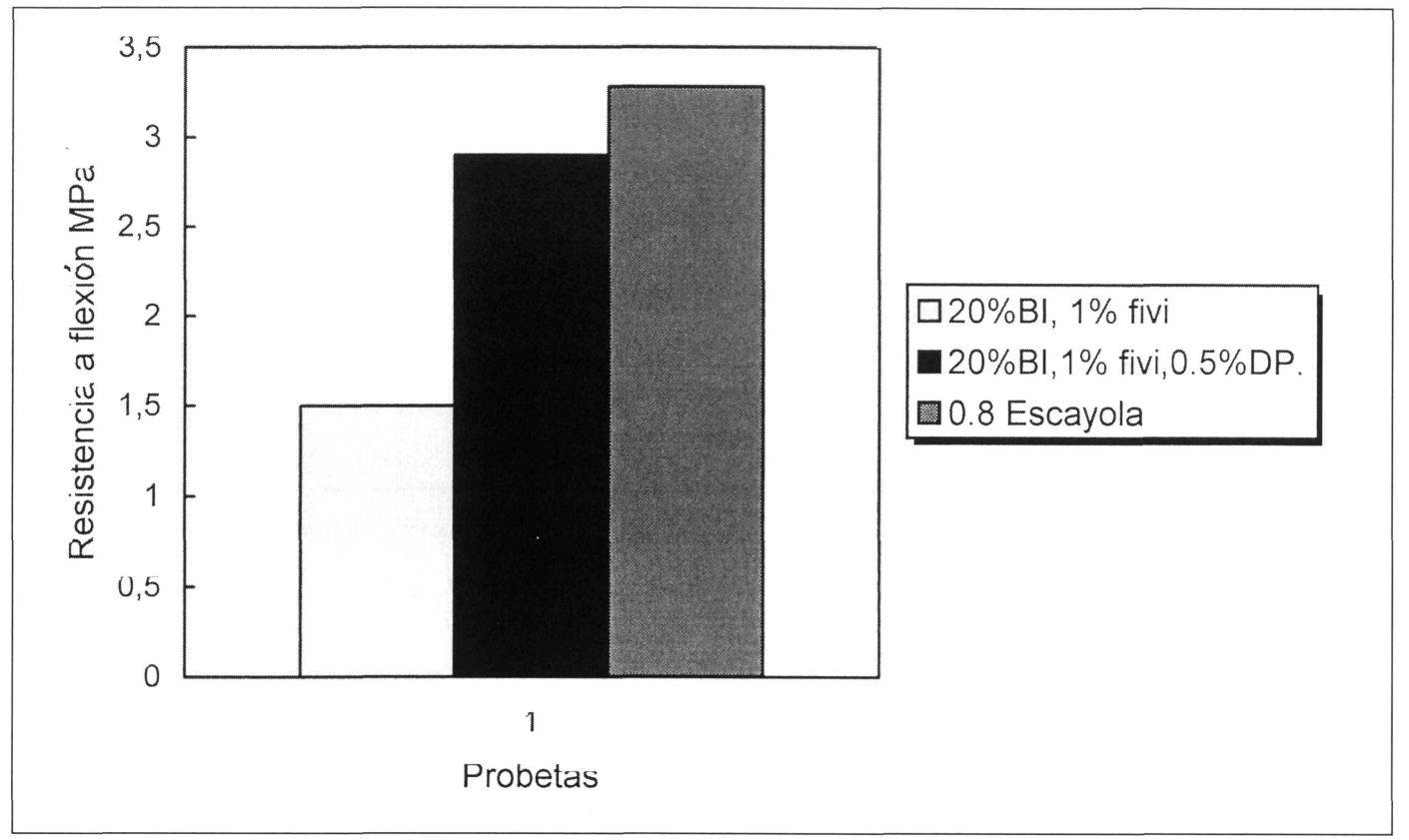

Figura 18.- Resistencia a flexión de las series de probetas, realizadas con y sin dispersiones poliméricas.

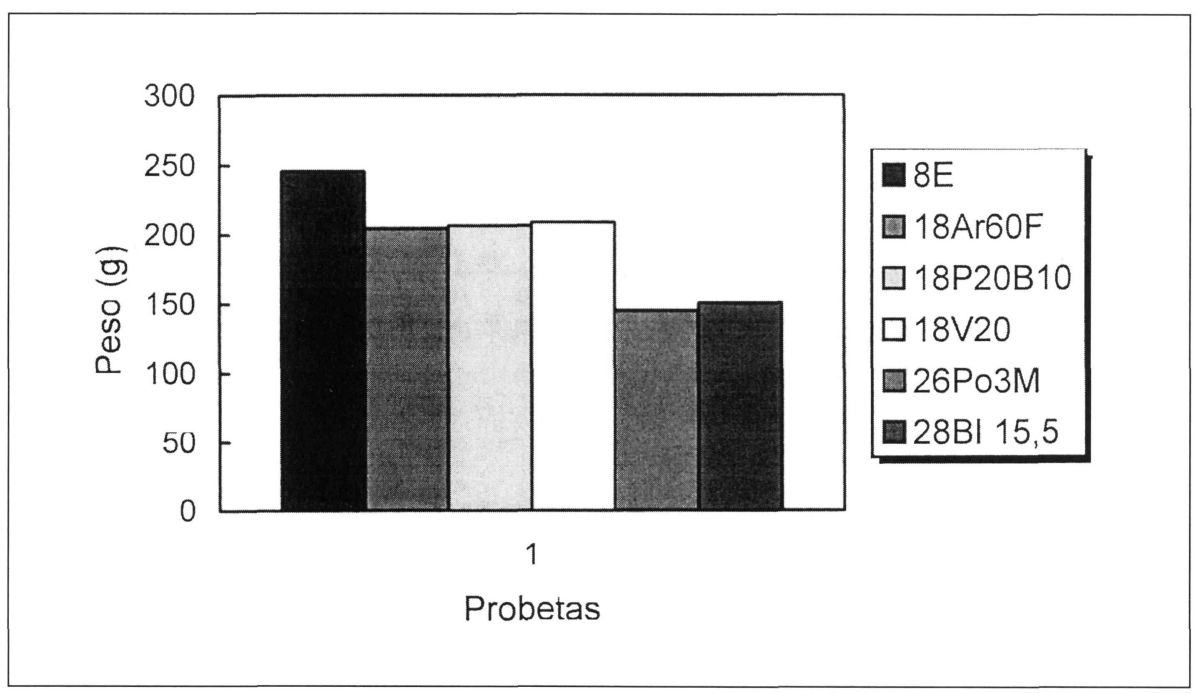

Figura 19.- Peso de las probetas de escayola + sólidos celulares.

Con el grupo de cargas, denominado, al principio, granulados ligeros, se consiguen disminuciones en el peso de las probetas aligeradas, frente a probetas de escayola sin aligerar, de hasta un $60 \%$, en los casos más favorables.

\section{Relación entre el peso de los compuestos y su resistencia a flexión}

En la figura 20 se recogen las relaciones entre el peso y la resistencia a flexión de las series más favorables realizadas con sólidos celulares.

De nuevo aparece claramente la diferenciación de los dos tipos de sólidos celulares añadidos, de forma que, el grupo

(c) Consejo Superior de Investigaciones Científicas Licencia Creative Commons 3.0 España (by-nc) de áridos ligeros, al tener mayor densidad, obtiene mejores resultados que el grupo de probetas realizadas con gránulos ligeros.

Destacar, en este segundo grupo, las probetas realizadas con corcho, ya que tienen una relación entre el peso y la resistencia a flexión muy conveniente, cuando se les refuerza con fibra de vidrio $\mathrm{E}$.

Relación entre el peso de los compuestos y su resistencia a compresión

En la figura 21 se observa cómo al grupo de probetas aligeradas con áridos ligeros, le corresponden los valores más altos de resistencia a compresión. Se destacan los 


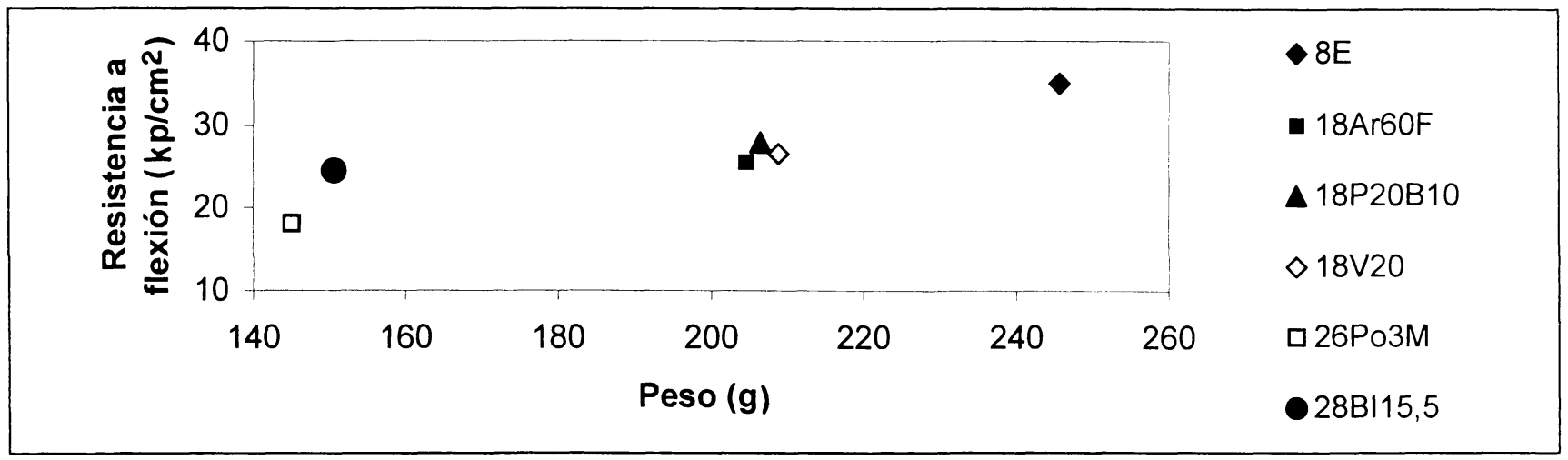

Figura 20.- Relación entre el peso y la resistencia a flexión de probetas de escayola aligeradas con sólidos celulares.

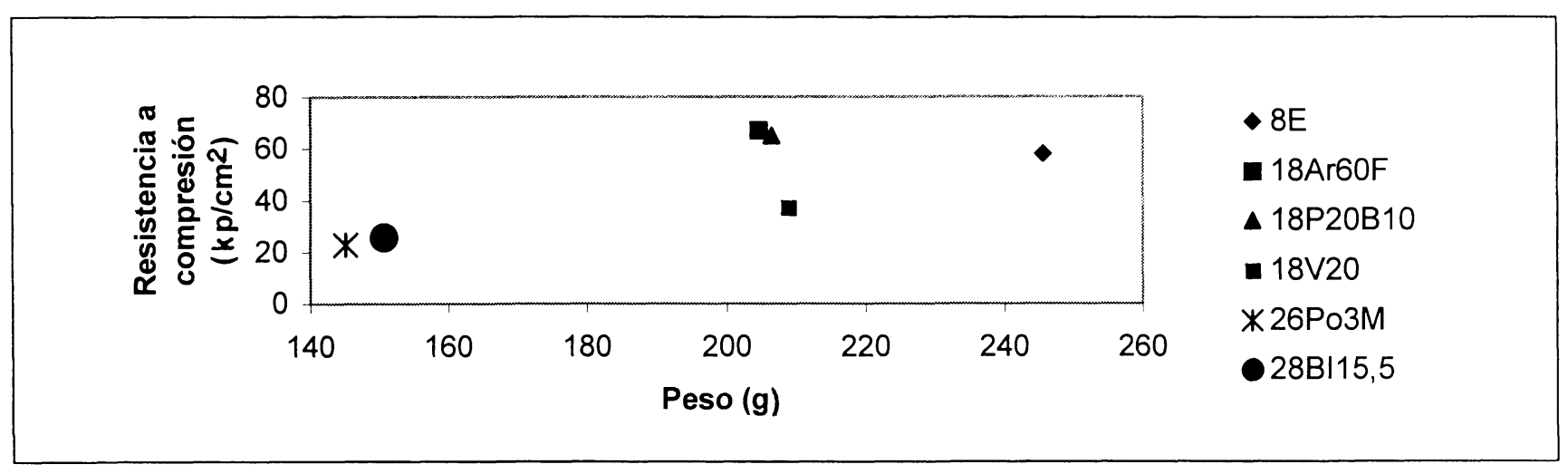

Figura 21.- Relación entre el peso y la resistencia a compresión de probetas de escayola aligeradas con sólidos celulares.

compuestos de escayola aligerada con perlita y arcilla expandida, donde, para una disminución importante del peso frente a probetas de escayola sin aligerar, se superan los valores de resistencia a compresión obtenidos por éstas.

El grupo de probetas de escayola aligeradas con gránulos ligeros, a pesar de estar reforzados con fibra de vidrio, no tienen una buena relación peso/resistencia a compresión, aunque consiguen mejorar la tenacidad frente a la escayola sin aligerar y, en el caso del compuesto escayola + corcho, se incrementa la capacidad de deformación previa a la rotura.

Se consideran válidos, por tanto, todos los compuestos estudiados y su elección dependerá, principalmente, de la aplicación constructiva que se pretenda.

\section{BIBLIOGRAFÍA}

(1) RY 85. Pliego general de recepción de yesos. M.O.P.U.

(2) ARLITA. Dossier técnico. Madrid.

(3) ARLITA. Manual general. Madrid 1993.

(4) Perlita. Manual de perlita expandida. Europerl.

(5) N.C. Clark. Mandoval Ltd. Vermiculite.

(6) J. Crisfield. HND. (BLDG) . Polystirene. Vencel Resil Ltd.

(7) UNE 56.911 .88

(8) Giles B. Cork \& the cork tree. Ed. Pergamon Press. 1961. Londres.

(9) Velasco Fdez. L. El corcho, material poliv. Ed.INIA. Madrid. 1978 